\title{
Evaluation of the position of mandibular third molar hidden teeth and its effect on second adjacent molar teeth in panoramic radiography in patients referring to Birjand Dental School in 2018-19
}

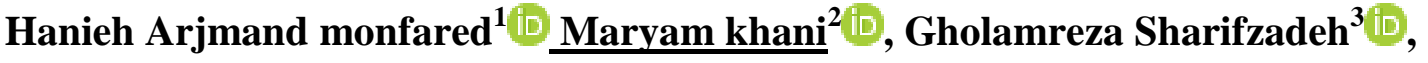 \\ Seyed Ramin Nourbakhsh ${ }^{4}$
}

\begin{abstract}
Background and Aim: The third molar tooth lies with symptoms such as periodontal problems, caries, crowding, root resorption, cyst and tumor formation of the adjacent second molar. This study was to evaluate the position of mandibular third molar teeth and its effect on second adjacent molar teeth.

Materials and Methods: Panoramic radiography was obtained from 264 patients with mandibular third molar hidden teeth referred to the Birjand School of Dentistry in 2018. The material and direction of their placement and the vertical position of the third molar tooth (based on the PELL \& Gregory classification) and its placement angle (based on Winter classification) were determined. Also, the prevalence of distal caries, external root resorption, the amounts of displacement, $t$ inflammatory lesions and the cystic was examined in the adjacent second molar tooth. Data were analyzed using SPSS software (Version 19), and Chi-square statistical test, $\mathrm{p}$-values less than 0.05 were considered as statistically significant.

Results: The data from this study showed that most of the wisdom hidden teeth were in Class B and III of Pell and Gregory classification, had Mesial angle based on Winter classification. In $20.8 \%$ of patients with caries, there was $3 \%$ root canal resorption and $1.1 \%$ displacement of the second molar tooth, while no cases of inflammatory and cystic lesions in the second molar tooth were found due to the hidden third molar tooth. The Mesial and horizontal angles of impacted wisdom teeth were associated with increased risk of caries and root resorption of the second molar. Also, Class B's third molar teeth increased caries in second molar teeth.

Conclusion: Most pathological problems were observed in Mesial, horizontal, and class B impaction. According to the observed relationship, it seems that the angle and depth of the hidden third molar should be taken into account $\mathrm{c}$ when deciding whether or not to extract it.
\end{abstract}

Key Words: Impaction, Mandibular Third Molar Hidden Teeth, Panoramic Radiography

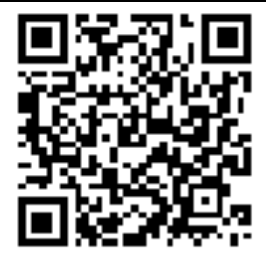

Citation: Khani M, Arjmand monfared H, Sharifzadeh Gh, Nourbakhsh R. [Evaluation of the position of mandibular third molar hidden teeth and its effect on second adjacent molar teeth in panoramic radiography in patients referring to Birjand Dental School in 2018-19]. J Birjand Univ Med Sci. 2020; 27(3): 291-300. [Persian]

DOI http://doi.org/10.32592/JBirjandUnivMedSci.2020.27.3.107

Received: June 8, 2020, Accepted: July 25, 2020

\footnotetext{
${ }^{1}$ Student Research Committee, Birjand University of Medical Sciences, Birjand, Iran.

${ }^{2}$ Oral and Maxillofacial Radiology, School of Dentistry, Birjand University of Medical Sciences, Birjand, Iran.

${ }^{3}$ Social Determinants of Health Research Center, Department of Public Health, Faculty of Health, Birjand University of Medical Sciences, Birjand, Iran.

${ }^{4}$ Oral and Maxillofacial Radiology, School of Dentistry, Birjand University of Medical Sciences, Birjand, Iran.

Corresponding author; Oral and Maxillofacial Radiology, School of Dentistry, Birjand University of Medical Sciences, Birjand, Iran.

rql
} 


\section{بررسى وضعيت دندان مولر سوم نهفته فك بايين و تأثير آن بر دندان مولر دوم مجاور در

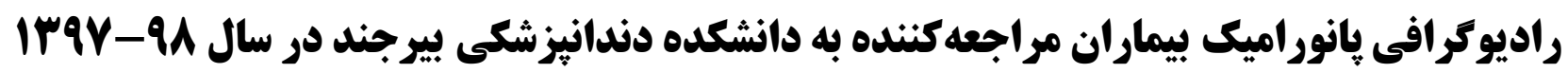

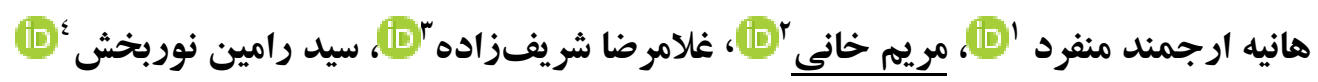

\section{جككيده}

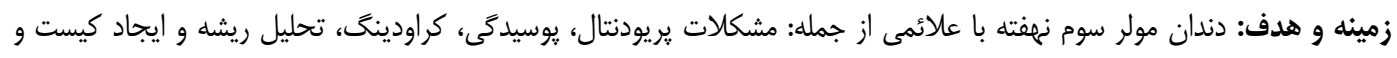

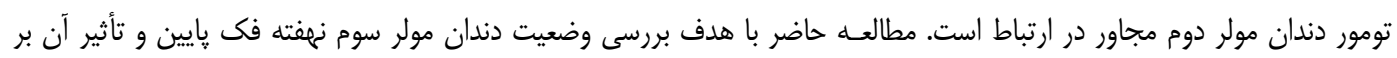

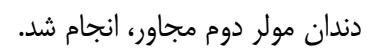

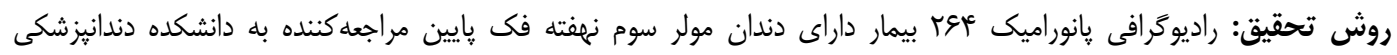

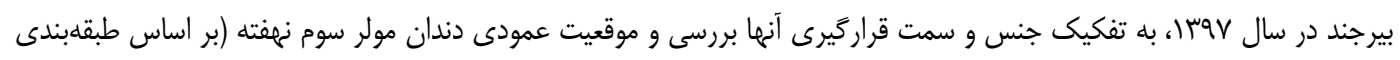
(PELL\& Gregory

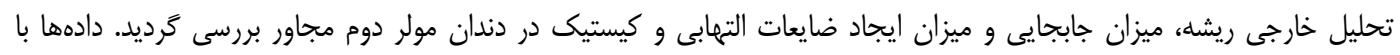

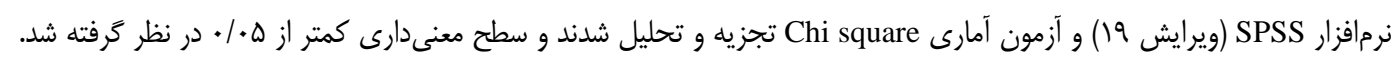

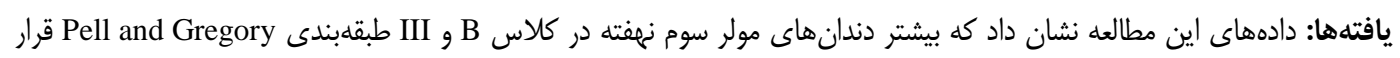

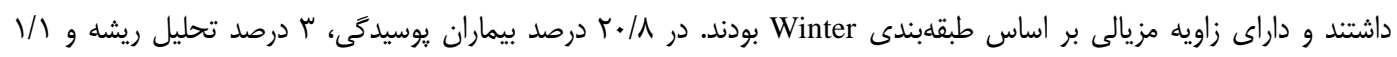

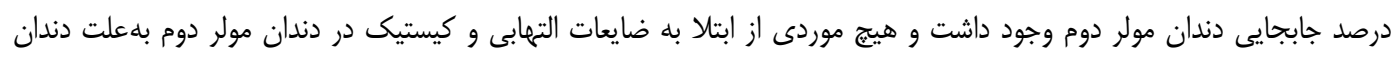

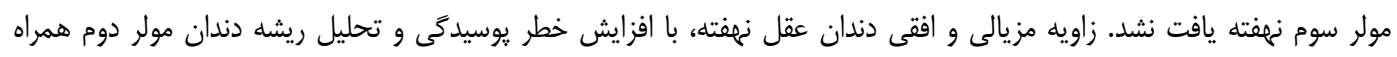

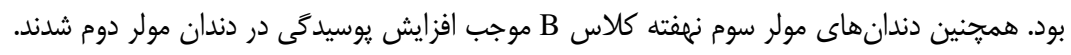

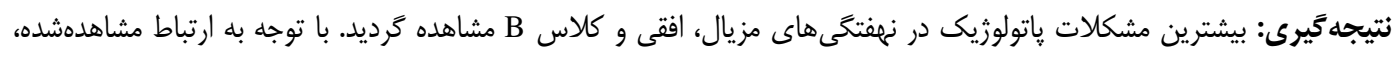

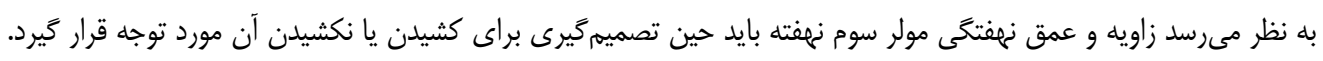

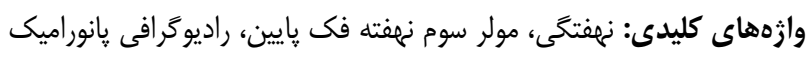

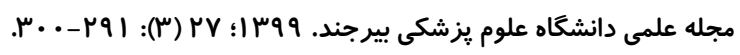
دريافت: 
دستورالعمل مشخص در رابطه با كشيدن بيشكيرانه دندان مقل مله

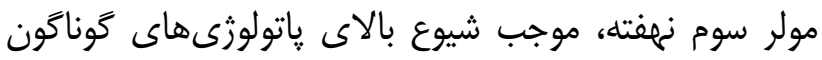

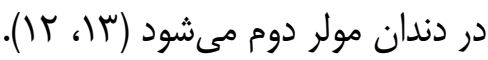

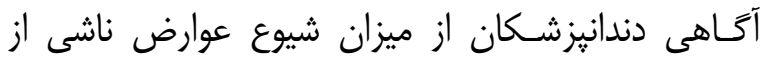

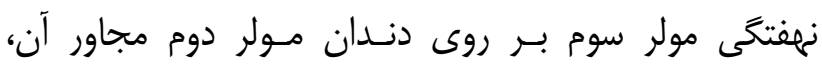

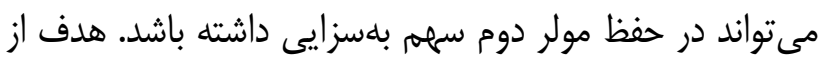
اين مطالسه، بررسى وضعيت دندان مولر سوم نهفتها فكى

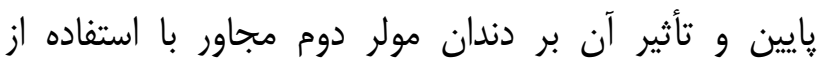

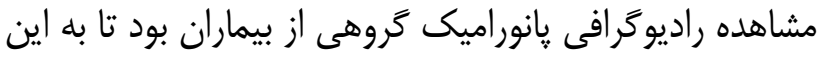
طريق بتوان با كشيدن بلموقع و درمان صحيح، براى حفظ دندان مولر دوم اقدام كرد.

\section{روش تحقيق}

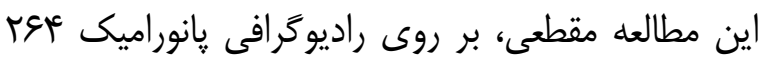
بيمار داراى دندان مولر سوم نهفته فكى بإيين مراجعاك كننده بـانه

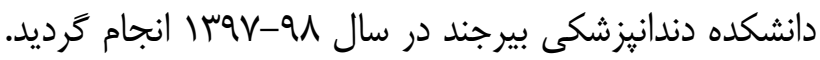
حجم نمونه به كمك رابطه (ا) و و با توجه به نتايج مطالعاله

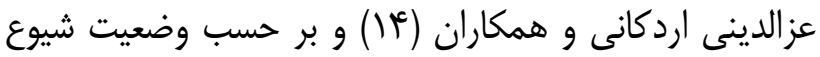

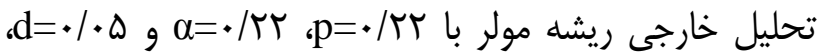

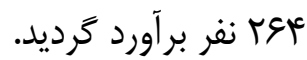

$$
n=\frac{z^{\mathrm{a}} p q}{d^{2}} \quad \text { رابطه }
$$

معيار ورود به مطالعه داشتن دندان مولر سوم نهفته فك الم

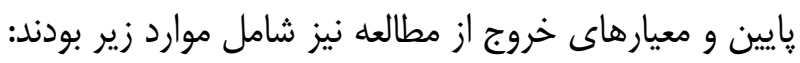

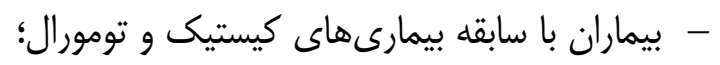

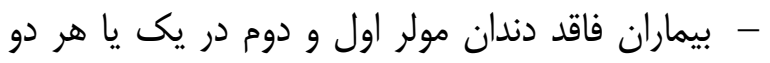
فك؛ - بيماران داراى دندان مولر سوم نهفته كه بلهصورت

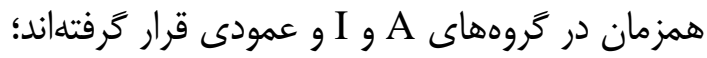
- بيماران داراى دندان مولر دوم درمان ريشه شده؛

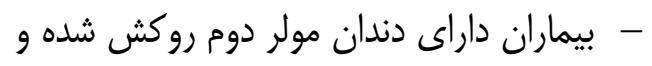
- بيماران داراى براكت روى مولر دوم مجاور دندان

هر دندانى كه دو سوم از ريشه آن تشكيلشده باشد ولى هنوز به سطح اكلوزال نرسيده باشد، نهفته (Impacted)

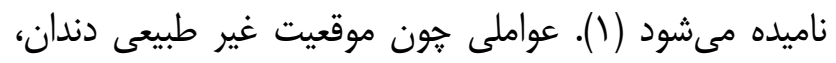

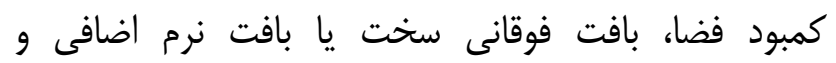

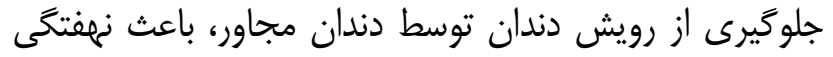

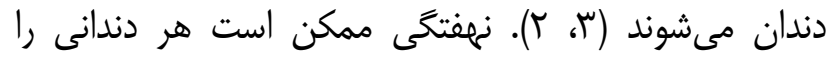

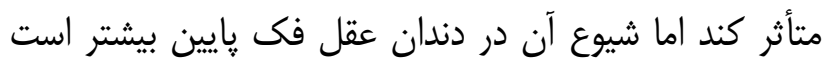

دندان مولر سوم نهفته، با علائمى از جمله: مشكلات

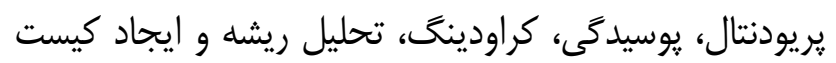

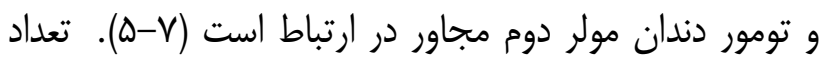

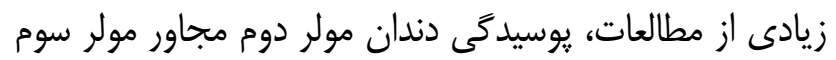

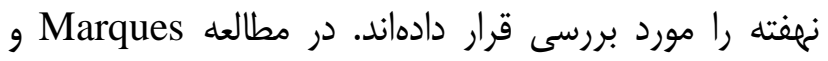

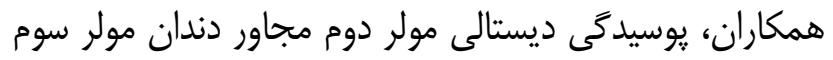

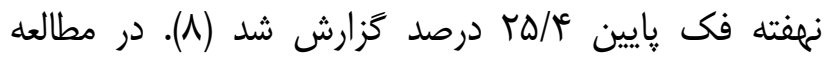
و و همكاران نيز اين ميزان Thang

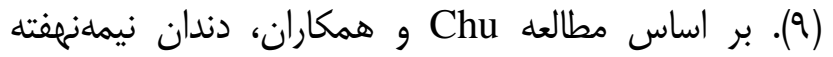

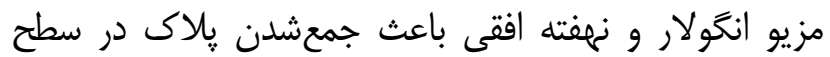

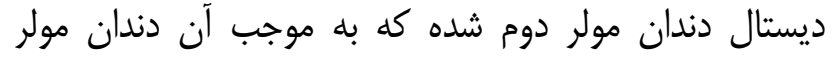

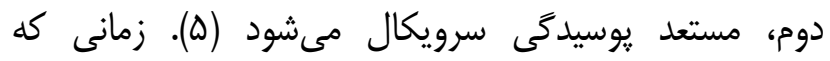

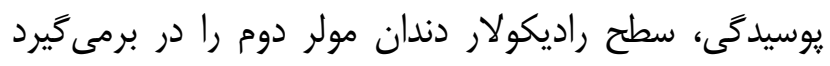

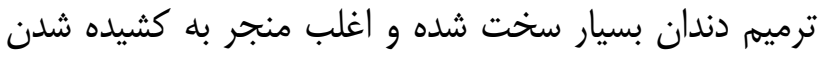
دندان مى كردد (·) (1). حضور مولر سوم نهفتله، ميزان استخوان

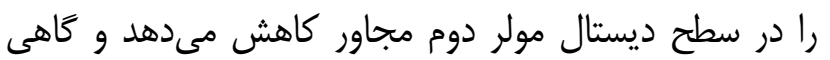

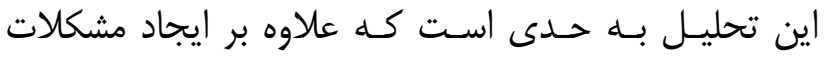

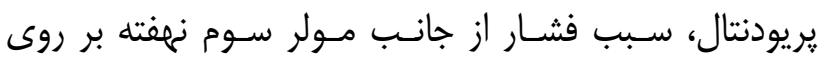

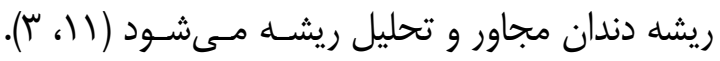
مطالعهاى كه به بررسى تأثير دندان مولر سوم نهانئه

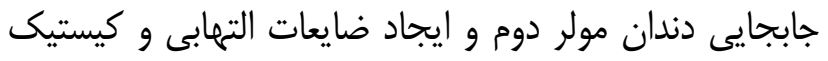
در اين دندان ببردازد يافت نشد. مطالعات مختلف نشان دان دان دان دادهاند كه دشوار بودن معاينه دندان مولر دوم و نبود إنبان 
- - - افقى: محور طولى مولر سوم نهفته كاملاً افقى است.

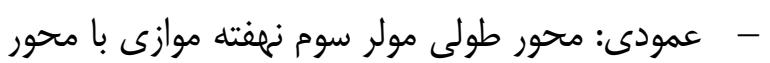

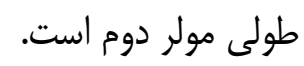
- معكوس: محور طولى مولر سوم نهفتله و دوم بلهورت موازى ولى در جهت عكس يكديكر قرار كرفتنهاند.

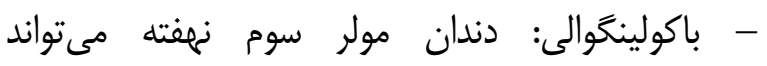

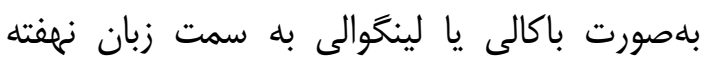

باشد.

دادههاى حاصل، وارد نرمافزار SPSS (ويرايش 19.0.1)

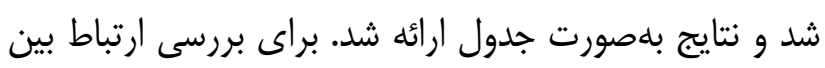

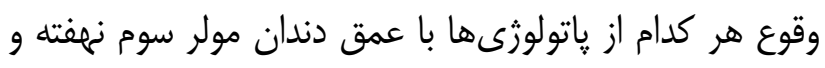

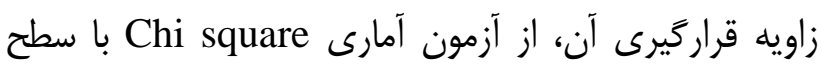

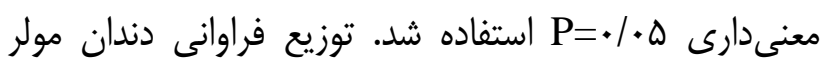

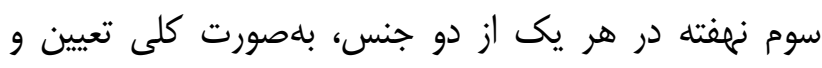

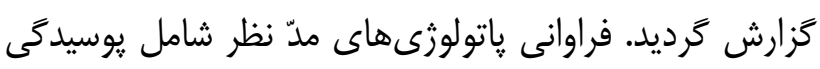

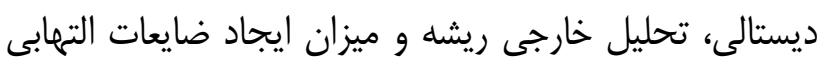

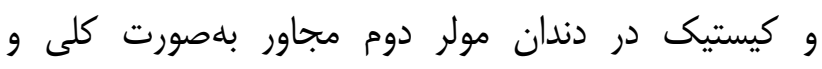

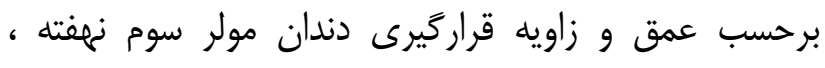
تعيين و كزارش كرديد. اين مقاله، بركرفنه از مطالعه داراى

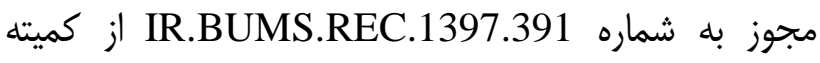
اخلاق دانشعاه علوم يزشكى بيرجند مىباشد.

\section{يافتهها}

بررسى فراوانى جنس و سمت قراركيرى دندان نهفته در

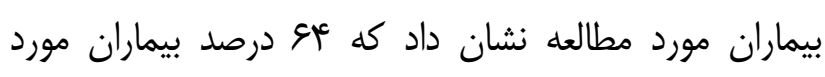

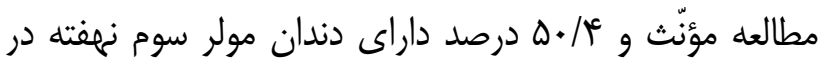

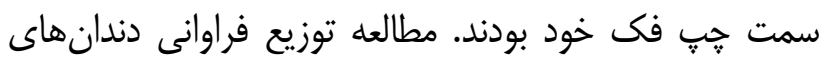
مولر سوم نهفته بر اساس طبقابندى Gregory

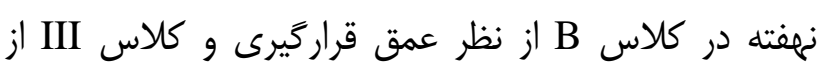

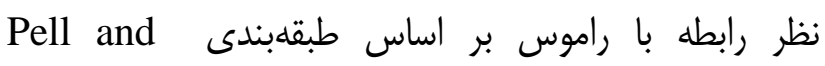

عقل. - مار

تصاوير راديوكرافى קانوراميك داراى دندان مولر سوم

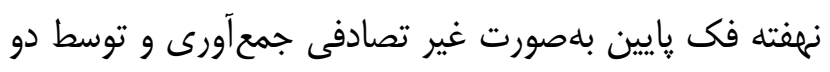

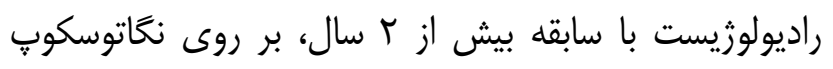

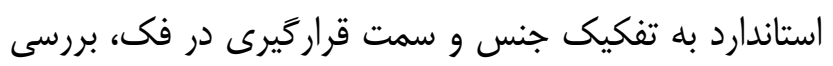

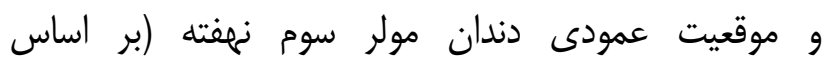

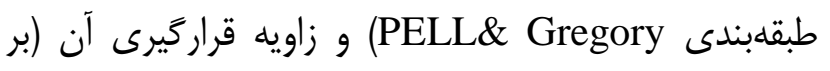
اساس طبقهبندى winter) مشخص شد.

\section{طبقهبندى PELL\& Gregory:}

- كلاس I: هيج قسمتى از تاج دندان نهفتلهى فك

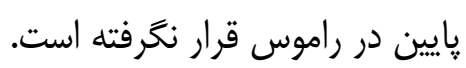

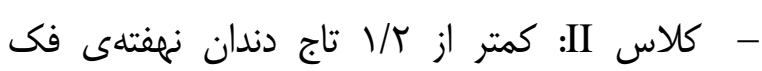
هايين در راموس قرار دارد. - كلاس III: بيشتر از بار دارد تاج دندان نهفتله فك دارد پايين در راموس قرار دارد. - كلاسA : بالاترين قسمت مولر سوم نهفته فك دارد

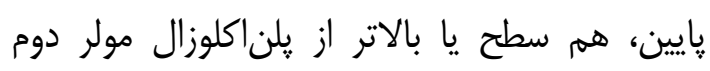
مجاور مىباشد. - كلاس B: بالاترين قسمت مولر سوم نهفته فك إند

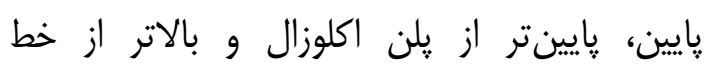

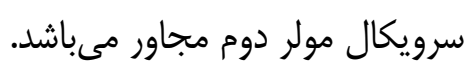

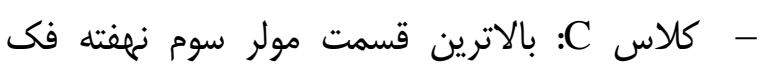
يايين، يايينتر از خط سرويكال مولر دوم مجاور

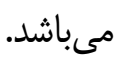

طبقلهبندى winter بر اساس تمايل دندان مولر سوم نهفته به سمت محور طولى دندان مولر دوم: مون

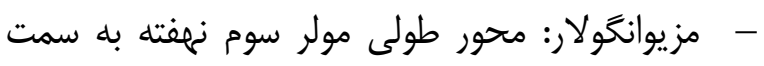
مولر دوم در جهت مزيال زاويه كرَفته است.

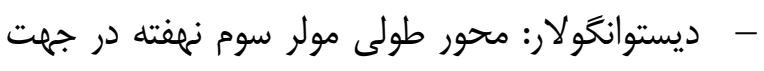
ديستال، به دور از محور طولى مولر دوم متمايل شده مولى نهو

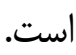


Gregory

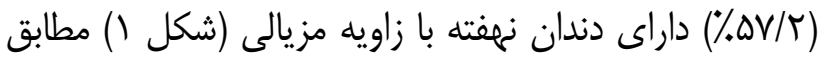

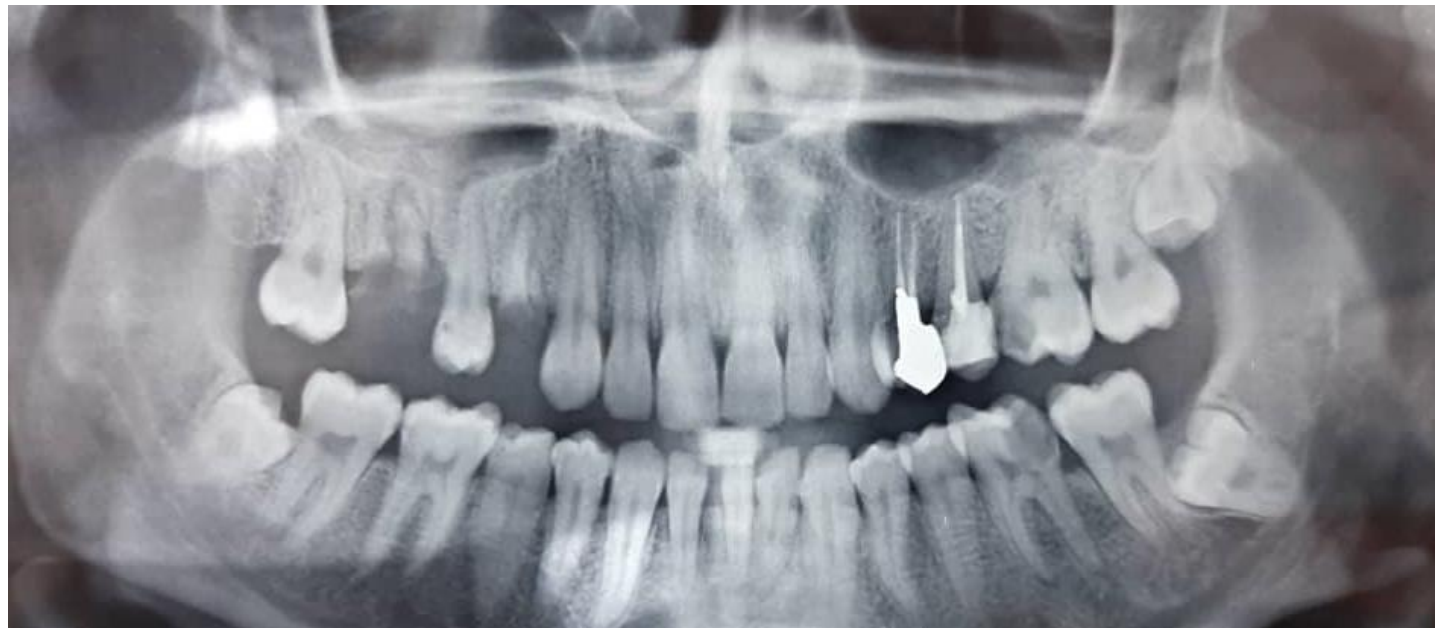

شكل ا- راديوكرافى يانور اميك با مولر سوم نهفته داراى زاويه مزيالى

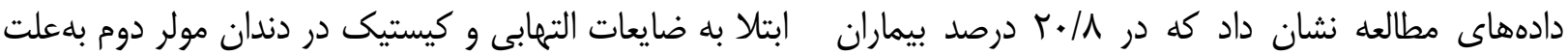
مورد مطالعه يوسيدگىى، در ץ درصد تحليل ريشه و در /// دندان مولر سوم نهفته مشاهده نشد.

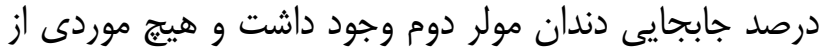

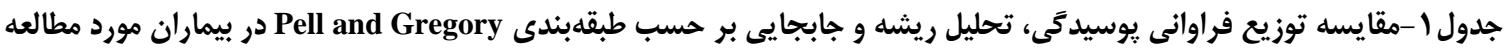

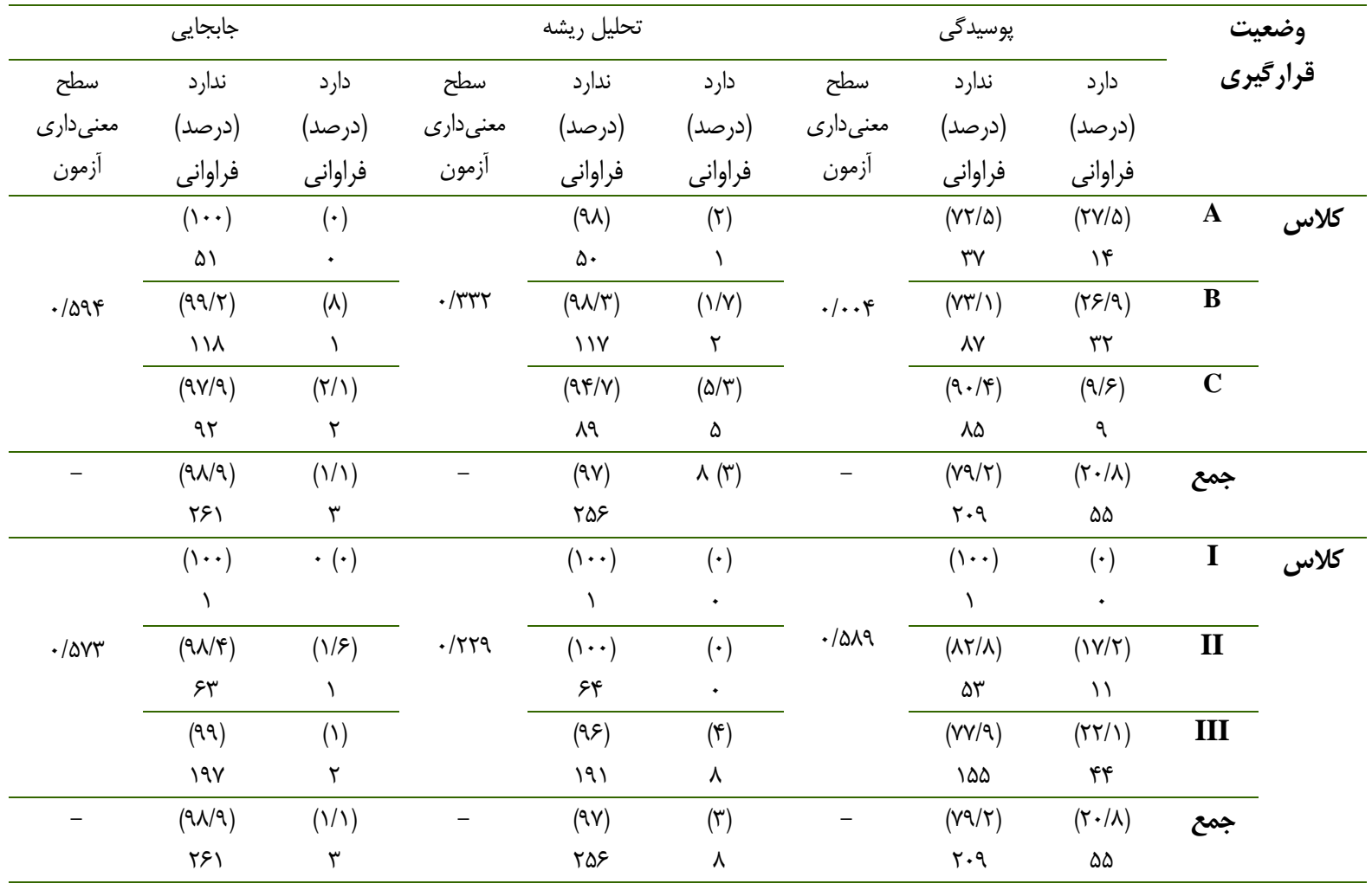


جدول r- مقايسه توزيع فراوانى يوسيدَّى، تحليل ريشه و جابجايى بر حسب طبقهبندى Winter در بيماران مورد مطالعه

\begin{tabular}{|c|c|c|c|c|c|c|c|c|c|}
\hline \multicolumn{3}{|c|}{ جابجايى } & \multicolumn{3}{|c|}{ تحليل ريشه } & \multicolumn{3}{|c|}{ يوسيدكى } & \multirow{4}{*}{ زاويه قرارَّيرى } \\
\hline \multirow{3}{*}{ معنى دارى } & ندارد & دارد & سطح & 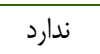 & دارد & سطح & ندارد & دارد & \\
\hline & (درصد) & (درصد) & معنى دارى & (درصد) & (درصد) & معنى دارى & (درصد) & (درصد) & \\
\hline & فراوانى & فراوانى & آزمون & فراوانى & فراوانى & آزمون & فراوانى & فراوانى & \\
\hline \multirow{10}{*}{ אז/I } & $(1 \cdot \cdot)$ & $(\cdot)$ & \multirow{10}{*}{. $1.4 t$} & $(94 / V)$ & $(1 / \Gamma)$ & \multirow{10}{*}{$<\cdot / \cdot+1$} & $\left(\Lambda V / T^{*}\right)$ & $(1 T / 9)$ & \multirow{2}{*}{ مزيال } \\
\hline & $|Q|$ & . & & $19 q$ & r & & rTI & 19 & \\
\hline & $(1 \cdot \cdot)$ & $(\cdot)$ & & $(1 \cdot \cdot)$ & $(\cdot)$ & & $(99 / \mathrm{V})$ & $(\Gamma / \%)$ & \multirow[t]{2}{*}{ ديستال } \\
\hline & r & . & & r & . & & r & 1 & \\
\hline & $(q \& / V)$ & $(\Gamma / \Gamma)$ & & $(q \cdot / r)$ & $(q / \Lambda)$ & & $(\Delta q)$ & $(F)$ & \multirow[t]{2}{*}{ افقى } \\
\hline & $\Delta q$ & r & & $\Delta \Delta$ & 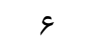 & & G & ra & \\
\hline & $(q \vee / \Lambda)$ & $(T / T)$ & & $(1 \cdot \cdot)$ & $(\cdot)$ & & $(\mathrm{VN} / \mathrm{r})$ & $(r / V)$ & \multirow[t]{2}{*}{ عمودى } \\
\hline & ia & 1 & & is & . & & G & 1. & \\
\hline & $(1 \cdot)$. & $(\cdot)$ & & $(1 \cdot \cdot)$ & $(\cdot)$ & & $(1 \cdots)$ & $(\cdot)$ & \multirow[t]{2}{*}{ معكوس } \\
\hline & r & . & & r & . & & r & . & \\
\hline \multirow[t]{2}{*}{-} & $(9 / / 9)$ & $(1 / 1)$ & & (9v) & $(\stackrel{\mu}{)})$ & - & $(\mathrm{VQ} / \mathrm{r})$ & $(r \cdot / \Lambda)$ & \multirow[t]{2}{*}{ جمع } \\
\hline & ral & r & & $T \Delta S$ & $\wedge$ & & $r . q$ & $\Delta \Delta$ & \\
\hline
\end{tabular}

بحث

دندان نهفته، طبق تعريف دندانى است كه به واسطه يك

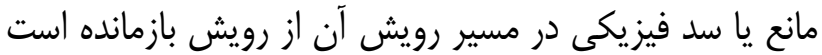

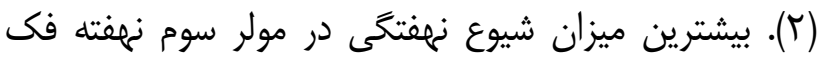

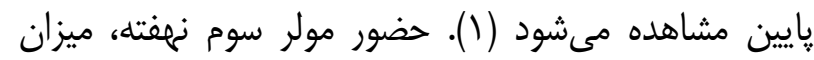

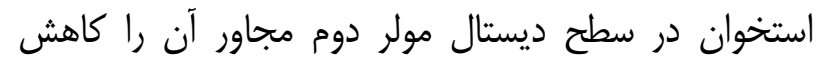
مىدهد و كاهى اين تحليل به حدى است كه علاوه بر ايجاد

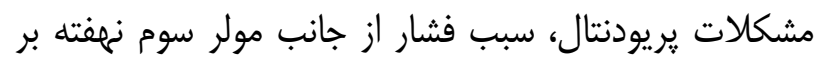

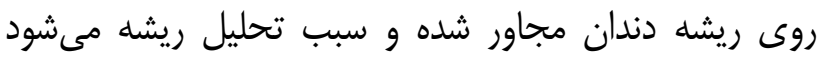
(ه). مطالعه حاضر با هدف بررسى وضعيت دندان مولر سوم نهفته فى يايين و تأثير آن بر دندان مولر دوم مجاور انجام

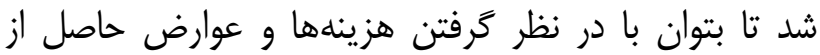

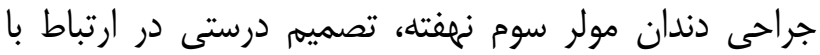
حذف يروفيلاكتيك مولر سوم نهفته اتخاذ كرد.

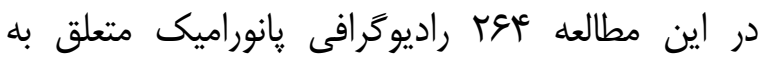
بيماران مراجعه كننده به كلينيك امام حسين (ع) شهر بيرجند

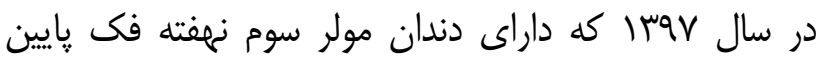

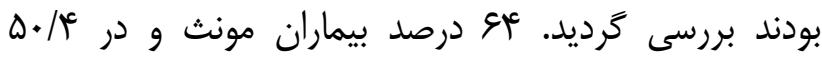

مطابق جدول يك، ارتباط معنىدارى بين عمق قرارگيرى

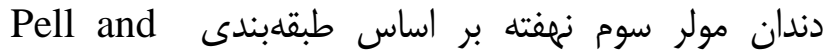
Gregory

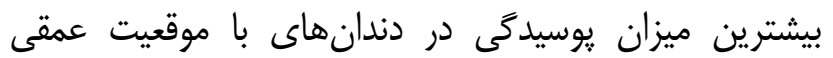

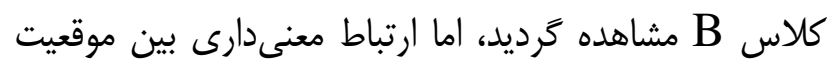

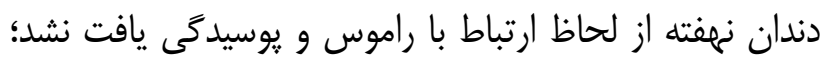

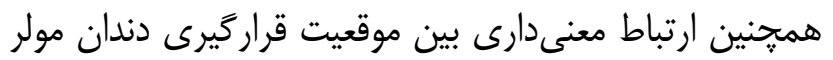

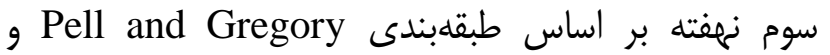
تحليل ريشه دندان مولر دوم مجاور و جابهجايى آن وجود استاس نداشت. بر اساس دادههاى جدول ז، ارتباط معنىدارى بين زاويه قرارگيرى دندان مولر سوم نهفته با يوسيدگى و تحليل ريشه دندان مجاور وجود داشت. بيشترين ميزان تحليل ريشه و ودئ يوسيدگى بلترتيب در دندانهاى با زاويه افقى و وزئو مزيال

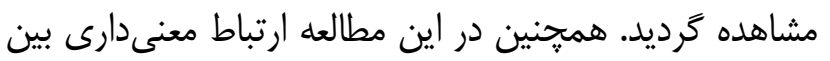
زاويه قرارگيرى دندان مولر سوم نهفته و جابجايى دندان مولر دماني

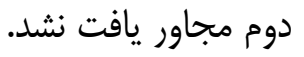




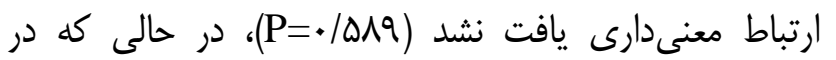

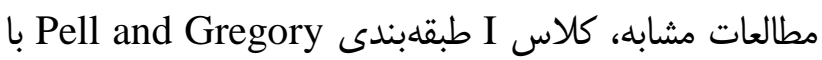
افزايش خطر يوسيدگى دندان مجاور در ارتباط بود (IN، IV)

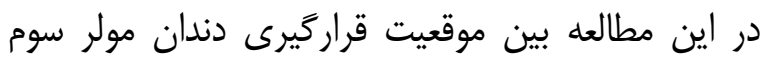

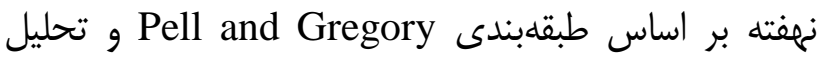

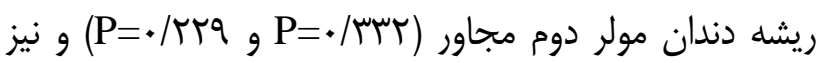

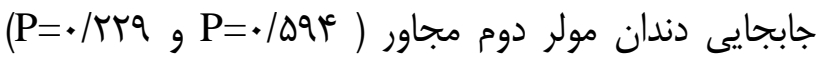
ارتباط معنىدارى وجود نداشت. بين زاويه قرارگيرى دندان دون دمان

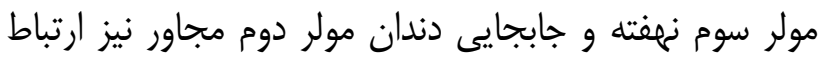

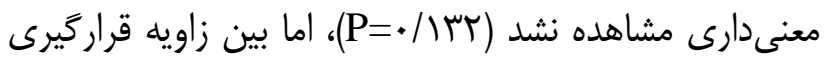
دندان مولر سوم نهفته و تحليل ريشه دندان مجاور ارندان ارتباط

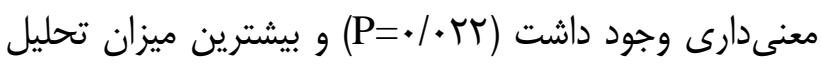
ريشه بلترتيب در دندانهاى با زاويه افقى و مزيالى مشاهده

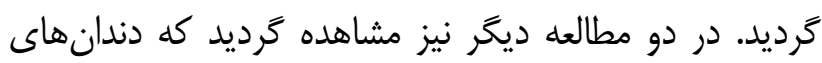

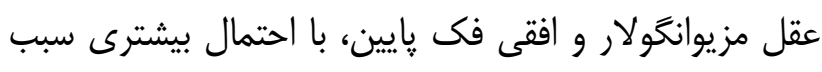
تحليل خارجى ريشه دندان مولر دوم مجاور خود مى مئنوند

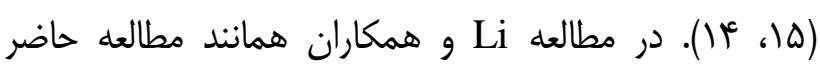

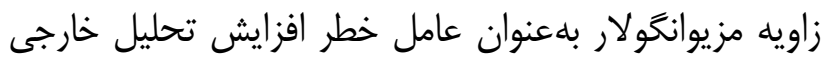

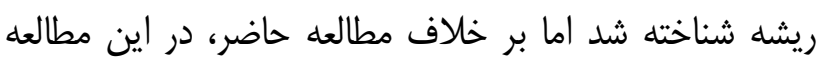

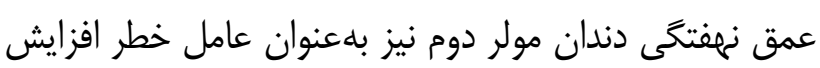

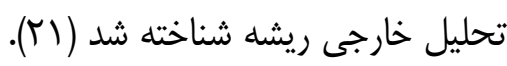

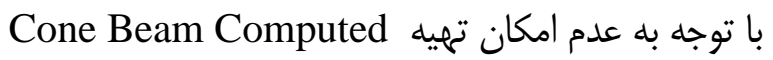
Tomography در شهر بيرجند، بررسى سلبعدى ميسّر نبود؛ بنابراين بهدليل عدم امكان بررسى دقيق ميزان تحليل

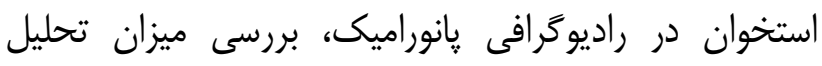
استخوان در مطالعه حاضر ميسر نخرديد. به طور كلى مى توان

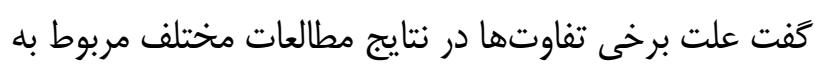

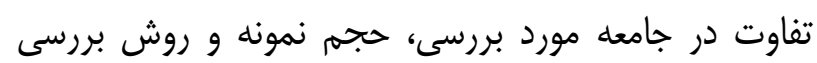
مىباشد.

\section{نتيجه كيرى}

نتايج اين مطالعه نشان مىدهد عمق و زاويه قرارگيرى
درصد آن ها دندان مولر سوم نهفته فى يايين در سمت جֶٍ فك قرار داشت.

يافتهاى مطالعه حاضر نشان داد كه بيشتر دندانهاى دان

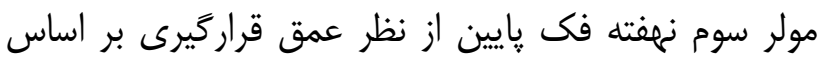

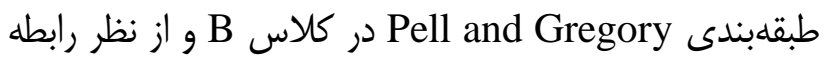
با راموس در كلاس III قرار داشتند. همجنين بيشتر بيماران

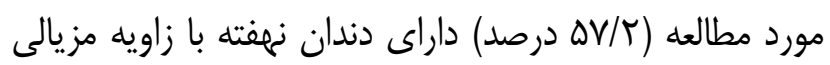
بر اساس طبقهبندى Winter بودند. بر اساس يافتههاى اين

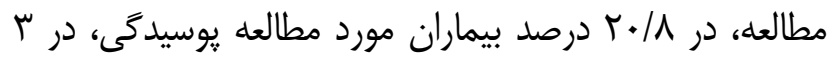

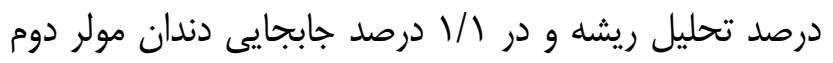

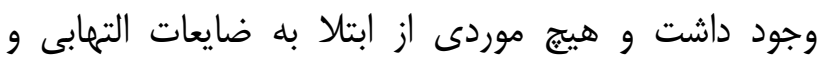
كيستيك در دندان مولر دوم بلعلت دندان مولر سوم نهفته يافت نشد. بر اساس يافتههاى اين مطالعه بين زاويه قرارگيرى

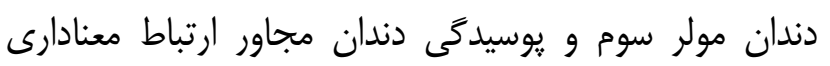

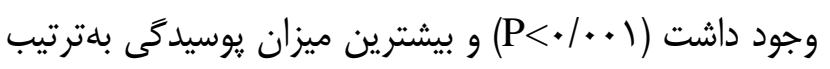

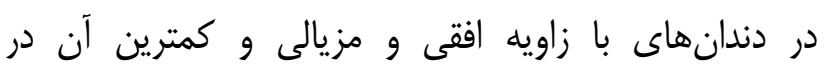
دندانهاى با موقعيت معكوس مشاهده شد. در ساير مطالعات

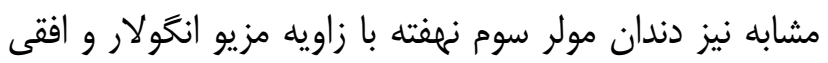

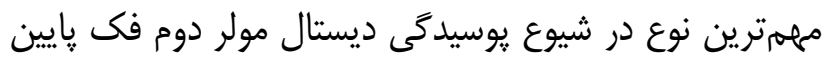

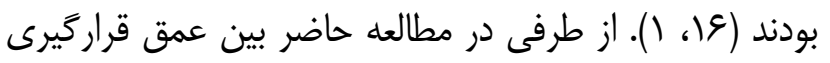

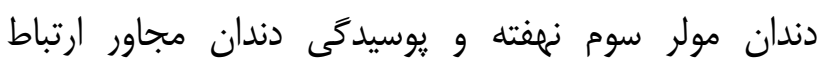

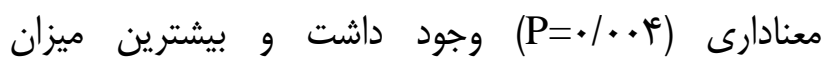

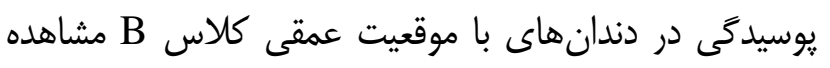

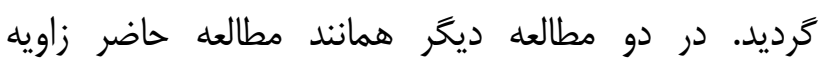

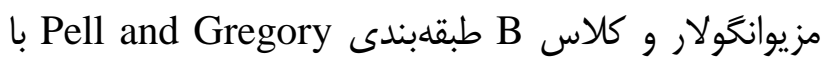

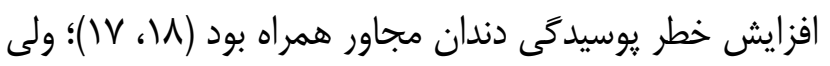

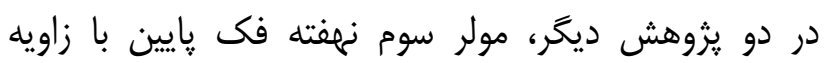

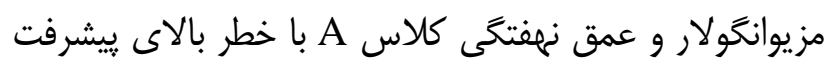
يوسيدگى مولرهاى دوم و سوم و آسيب بافت يريودنتال دندان

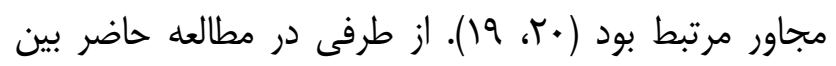

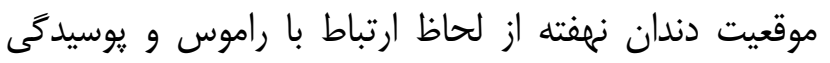




$$
\begin{aligned}
& \text { دندان مولر سوم نهفته، با يوسيدگى دندان مجاور در ارتباط تقدير و تشكر }
\end{aligned}
$$

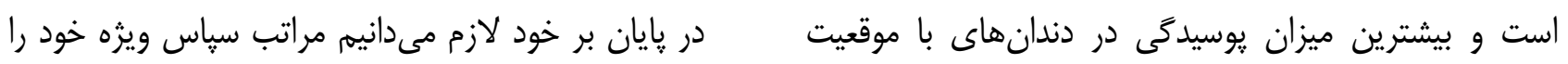

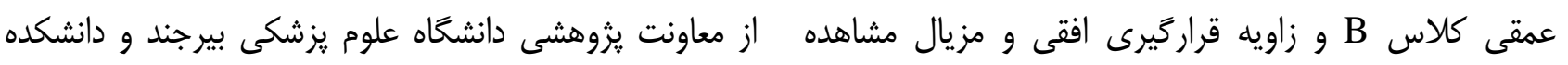

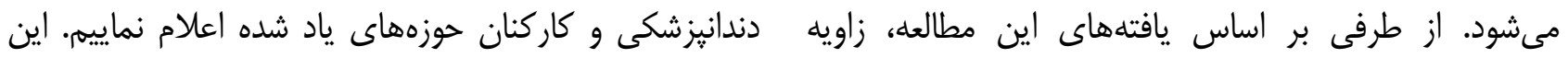

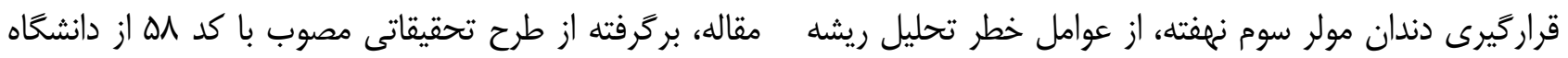

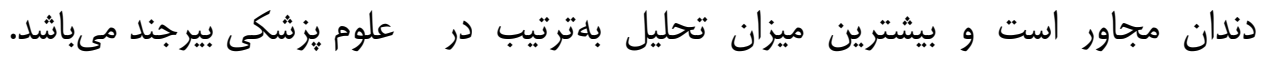

$$
\begin{aligned}
& \text { دندانهاى با زاويه افقى و مزيالى قابل مشاهده است. بنابراين }
\end{aligned}
$$

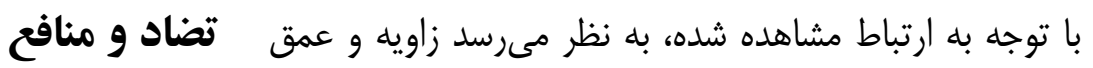

$$
\begin{aligned}
& \text { نويسندكان اين مقاله اعلام مىدارند كه هيجز مونه تضاد } \\
& \text { منافعى در مطالعه حاضر وجود ندارد. }
\end{aligned}
$$

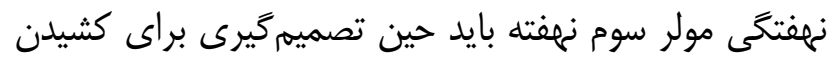

$$
\begin{aligned}
& \text { يا نكشيدن آن مورد توجه قرار كيرد. }
\end{aligned}
$$

\section{منابع:}

1- Bokhari Syed K, Alshahrani FS, Alabsi WS, AlQahtani ZA, Hameed MS, Mustafa AB, et al. Prevalence of distal Caries in mandibular second molar due to impacted third molar. Journal of clinical and diagnostic re J Clin Diagn Res. 2017; 11(3): ZC28-30. doi: 10.7860/JCDR/2017/18582.9509

2- Neville BW, Damm DD, Allen CM, Bouquoti E. Oral and maxillofacial pathology. $2^{\text {nd }}$ ed. Philadelphaia: WB Saunders; 2002.

3- Peterson LJ, Eliss E, Hupp JR, tucker MR. Contemporary oral and maxillofacial surgery. $4^{\text {th }}$ ed. St Louis: CV Mosby; 2003.

4- Ventä I, Schou S. Accuracy of the Third Molar Eruption Predictor in predicting eruption. Oral Surg Oral Med Oral Pathol Oral Radiol Endod. 2001; 91(6): 638-42. doi: 10.1067/moe.2001.113350

5- Chu FC, Li TK, Lui VK, Newsome PR, Chow RL, Cheung LK. Prevalence of impacted teeth and associated pathologies-a radiographic study of the Hong Kong Chinese population. Hong Kong Med J. 2003; 9(3): $158-63$.

6- Pedro FLM, Bandéca MC, Volpato LER, Marques ATC, Borba AM, de Musis CR, et al. Prevalence of impacted teeth in a Brazilian subpopulation. J Contemp Dent Pract. 2014; 15(2): 209-13. doi: 10.5005/jp-journals-10024-1516

7- Campbell JH. Pathology associated with the third molar. Oral Maxillofac Surg Clin North Am. 2013;25(1): 1-10, v. doi: 10.1016/j.coms.2012.11.005.

8- Marques J, Montserrat-Bosch M, Figueiredo R, Vilchez-Pérez MA, Valmaseda-Castellón E, Gay-Escoda C. Impacted lower third molars and distal caries in the mandibular second molar. Is prophylactic removal of lower third molars justified? J Clin Exp Dent. 2017; 9(6): e794-98. doi: 10.4317/jced.53919.

9- Chang SW, Shin SY, Kum, KY, Hong J. Correlation study between distal caries in the mandibular second molar and the eruption status of the mandibular third molar in the Korean population. Oral Surg Oral Med Oral Pathol Oral Radiol Endod.2009; 108(6): 838-43. doi: 10.1016/j.tripleo.2009.07.025.

10- Banks RJ. Summary of: The mesioangular third molar-to extract or not to extract? Analysis of 776 consecutive third molars. Br Dent J. 2009; 206(11): 586-7. doi: 10.1038/sj.bdj.2009.491

11- Newman MG, Takei HH, Carranza FA. Clinical periodontology. $9^{\text {th }}$ ed. Philadelphia: W.B Saunders; 2002.

12- Bouloux GF, Busaidy KF, Beirne OR, Chuang SK, Dodson TB. What is the risk of future extraction of asymptomatic third molars? A systematic review. J Oral Maxillofac Surg. 2015; 73(5): 806-11. doi: 10.1016/j.joms.2014.10.029. 
13- Ghaeminia H, Nienhuijs MEL, Toedtling V, Perry J, Tummers M, Hoppenreijs TJM, et al. Surgical removal versus retention for the management of asymptomatic disease-free impacted wisdom teeth. Cochrane Database Syst Rev. 2020; (5): CD00003879. DOI: 10.1002/14651858.CD003879. pub5.

14- Ezoddini Ardakani F, Safi Y, Jamali G. Morphometric evaluation of external root resorption of mandibular second molar teeth adjacent to the impacted third molars in CBCT imaging of Tehran's population between 2011-2014. J Shahid Sadoughi Univ Med Sci. 2017; 25(1): 63-72. [Persian]

15- Tassoker M. What Are the Risk Factors for External Root Resorption of Second Molars Associated With Impacted Third Molars? A Cone-Beam Computed Tomography Study. J Oral Maxillofac Surg. 2019; 77(1): 11-7. doi: 10.1016/j.joms.2018.08.023.

16- Fallahi HR, Dabaghi A, Almasi NK. Investigating the relationship between the type of impaction ofmandibular third molars and the caries of distal surface ofmandibular second molars. Jundishapur Sci Med J. 2017; 16(5): 54753. [Persian]

17- Srivastava N, Shetty A, Goswami RD, Apparaju V, Bagga V, Kale S. Incidence of distal caries in mandibular second molars due to impacted third molars: Nonintervention strategy of asymptomatic third molars causes harm? A retrospective study. Int J Appl Basic Med Res. 2017; 7(1): 15-30. doi:10.4103/2229-516X.198505

18- Prajapati VK, Mitra R, Vinayak KM. Pattern of mandibular third molar impaction and its association to caries in mandibular second molar: A clinical variant. Dent Res J (Isfahan). 2017; 14(2): 137-45.

19- Matzen L, Schropp L, Spin-Neto R, Wenzel A. Radiographic signs of pathology determining removal of an impacted mandibular third molar assessed in a panoramic image or CBCT. Dentomaxillofacial Radiology. 2017;46(1):20160330.

20- Glória JCR, Martins CC, Armond ACV, Galvao EL, Dos Santos CRR, Falci SGM. Third molar and their relationship with caries on the distal surface of second molar: a meta-analysis. Journal of maxillofacial and oral surgery.2018; 17(2): 129-41. doi: 10.1007/s12663-017-1032-9

21- Li D, Tao Y, Cui M, Zhang W, Zhang X, Hu X. External root resorption in maxillary and mandibular second molars associated with impacted third molars: a cone-beam computed tomographic study. Clin Oral Investig. 2019; 23(12): 4195-4203. doi: 10.1007/s00784-019-02859-3. 